Article

\title{
Novel Method of the Seal Aerodynamic Design to Reduce Leakage by Matching the Seal Geometry to Flow Conditions
}

\author{
Damian Joachimiak \\ Institute of Thermal Engineering, Poznan University of Technology, 60-965 Poznan, Poland \\ damian.joachimiak@put.poznan.pl; Tel.: +48-61-665-22-09
}

check for updates

Citation: Joachimiak, D. Novel Method of the Seal Aerodynamic Design to Reduce Leakage by Matching the Seal Geometry to Flow Conditions. Energies 2021, 14, 7880. https://doi.org/10.3390/en14237880

Academic Editor: Artur Bartosik

Received: 6 October 2021

Accepted: 18 November 2021

Published: 24 November 2021

Publisher's Note: MDPI stays neutral with regard to jurisdictional claims in published maps and institutional affiliations.

Copyright: (C) 2021 by the author. Licensee MDPI, Basel, Switzerland. This article is an open access article distributed under the terms and conditions of the Creative Commons Attribution (CC BY) license (https:// creativecommons.org/licenses/by/ $4.0 /)$.

\begin{abstract}
This paper presents a novel method of labyrinth seals design. This method is based on CFD calculations and consists in the analysis of the phenomenon of gas kinetic energy carry-over in the seal chambers between clearances. The design method is presented in two variants. The first variant is designed for seals for which it is impossible to change their external dimensions (length and height). The second variant enables designing the seal geometry without changing the seal length and with a slight change of the seal height. Apart from the optimal distribution of teeth, this variant provides for adjusting chambers geometry to flow conditions. As the result of using both variants such design of the seal geometry with respect to leakage is obtained which enables achieving kinetic energy dissipation as uniform as possible in each chamber of the seal. The method was developed based on numerical calculations and the analysis of the flow phenomena. Calculation examples included in this paper show that the obtained reduction of leakage for the first variant ranges from $3.4 \%$ to $15.5 \%$, when compared with the initial geometry. The relation between the number of seal teeth and the leakage rate is also analyzed here. The second variant allows for reduction of leakage rate by $15.4 \%$, when compared with the geometry with the same number of teeth. It is shown that the newly designed geometry reveals almost stable relative reduction of leakage rate irrespective of the pressure ratio upstream and downstream the seal. The efficiency of the used method is proved for various heights of the seal clearance.
\end{abstract}

Keywords: labyrinth seal; leakage; design method; kinetic energy; inverse problem; steam turbines; gas turbines; fluid-flow machines

\section{Introduction}

Labyrinth seals are widely used in various types of fluid-flow machines, such as steam turbines, gas turbines, and compressors. Labyrinth seals enable reducing the leakage of working medium between two elements that are non-contacting. Concern for the protection of the natural environment imposes current trends to achieve greater efficiency of flow machines and flowing systems. High parameters of machines operation are required, which means that seals work in the environment characterized by high temperatures and large pressure drop. Labyrinth seals have particular impact on the efficiency of high powergenerating machines. In the paper [1], the impact of the leakage in the internal gland of the steam turbine $13 \mathrm{~K} 215$ on the power loss was analyzed. It was showed that the power loss resulting from the steam leakage through the internal seal of nominal geometry had achieved approx. $1 \mathrm{MW}$, and through the worn out seal it could achieve $2 \mathrm{MW}$. Therefore, the problem of leakage minimization is of great importance. The paper [2] presented the numerical analysis of fluid flow in the two-teeth straight through over-bandage seal in the axial turbine stage, with particular attention to the impact of the leakage on the main flow. Authors of this paper showed that the leakage had a considerable impact on the agitation loss and secondary flows generating serious energy losses in the turbine stage. It was proved in the paper [3] that 1\% increase in the seal-tooth clearance height causes a significant decrease in performance and efficiency of the multistage axial compressor. Labyrinth seals also have a great influence on the efficiency of reciprocating machines [4-6]. 
Various calculation methods for estimating the leakage rate in the labyrinth seal are presented in the scientific literature. The first calculation model describing the gas flow in the straight through seal was developed by Martin [7]. Egli [8] and other researchers, Hodkinson [9], Zimmermann and Wolff [10], had included in their calculation models the phenomenon of kinetic energy carry over as well as the result of flow contraction. Those models were next developed by Neumann [11] and Scharrer [12], among others, who proposed the method for calculating the seal leakage tooth by tooth. There are new one-dimensional models appearing in the literature [13,14], enabling the determination of supercritical $\mathrm{CO}_{2}$ leakage. The most advanced of these models provide for such features of the seal geometry as the clearance height, chamber length, and tooth thickness. These methods have different accuracy which depends on coefficients being determined experimentally. Applying the above-mentioned models to analyze the seal geometry in order to optimize it with respect to the leakage rate would be subjected to great error, which was proved in the paper [15].

Usage of the CFD flow analysis enables better observation of physical and flow phenomena, which in turn enables designing seals of higher leak tightness. In papers [16-20], the impact of the seal geometric parameters, such as the pitch or the chamber size, on the leakage rate was described. The degree of sealing wear and tear has a considerable impact on the failure of the seal integrity [21-23]. Slight changes in the dimensions of the clearance influence the leakage value and the flow coefficients, which is presented in the paper [24]. A seal with staggered helical teeth, which is characterized by reduced leakage, is presented in the paper [25]. In the paper [26], the reduction of leakage is achieved by slight changes in the chamber geometry, which were disturbing the gas jet flowing with high velocity. Surrogate models of optimization based on a set of input data, which features had been specified parametrically, obtained from CFD calculations, are discussed in the paper [27]. Radial clearance height and teeth spacing were variable parameters. The leakage minimization and decreasing total increase of enthalpy resulting from the friction were taken as the optimization criterion. The paper [28] presents the method for optimizing the straight through sealing with the use of CFD by changing the teeth inclination angle and spacing. The paper [29] presents an optimization model taking into account such design variables as the seal clearance, teeth width, teeth height, pitch, and teeth backward and forward expansion angle. The problem of optimizing the geometry of seal chambers is considered in the paper [30]. Semi-empirical model and parametric CFD analysis were used for this purpose. In the paper [15], the impact of the increasing number of teeth for constant length of the straight through seal on the leakage rate is investigated. Data presented therein indicate that there is a specific range of the seal pitch length in the straight through seal for which the minimum leakage is obtained. The increase of the number of seal teeth results in the decrease of pitch length and reduction of chambers size. It was proved in the paper [9] that the application of too many teeth leads to the effect of increasing leakage in the seal. This is the result of fading gas expansion in chambers of reducing size. Then the flow character becomes similar to that in the slot seal [31]. In this paper a new method for designing the geometry of the labyrinth seal is described. The inspiration for research work presented herein was to develop a relatively simple in-use method for designing such seal geometry which is based on the observation of flow phenomena intensifying leakage. So far, seals with equal chamber dimensions or with sequentially repeated chambers were designed.

The approach to designing seals by matching the seal geometry to flow conditions, and particularly based on the analysis of the gas kinetic energy distribution along the seal length, has not yet been presented in scientific literature. The method for labyrinth seal design, presented in this paper, enables quick obtaining of results. It enables determination of many dimensions of the geometry in one calculation step. Application of this method results in obtaining the geometry with a lower leakage than the geometry with the same external dimensions and teeth being spaced evenly (variant $A$ ) or the geometry with slightly increased chambers height (variant B). This problem belongs to the group of geometry-related inverse problems [32,33]. 


\section{Method of Aerodynamic Design}

The leakage rate in sealing is strongly affected by the gas expansion in clearances and by the gas kinetic energy dissipation in chambers. Gas flowing through subsequent clearances expands, which results in the density reduction. The relation between the clearance height and the pressure distribution in the straight-through seal was presented in the paper [34]. In each subsequent clearance the gas velocity is higher and higher (Figure 1). Widely used labyrinth seals are characterized by constant chamber size.

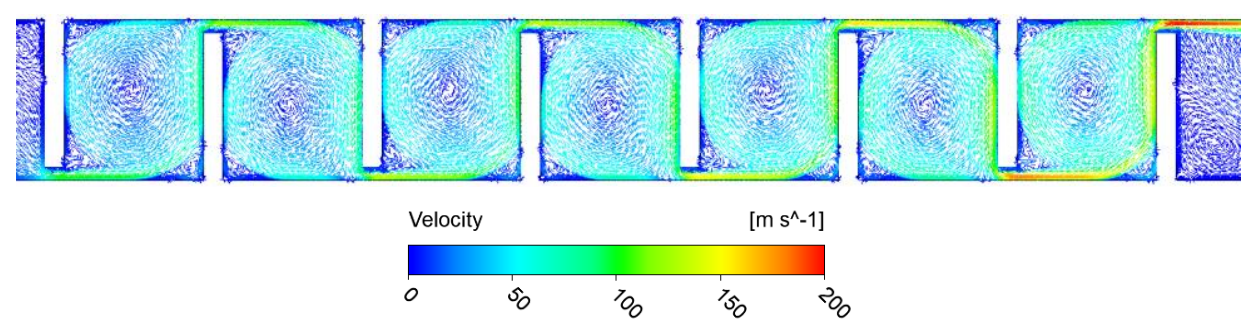

Figure 1. Example vectors of velocity fields in a representative segment for $p_{\text {in }} / p_{\text {out }}=2$ and $T_{\text {in }}=300 \mathrm{~K}$, $p_{\text {out }}=10^{5} \mathrm{~Pa}$.

In the seal chambers of constant dimensions one can observe the unequal degree of gas kinetic energy dissipation. The measure of the gas kinetic energy dissipation in chambers is the kinetic energy carry-over coefficient, which was analyzed in the paper [35]. The phenomenon of the gas kinetic energy carry-over has a great impact on the leakage rate [36-38]. The idea of a novel method of aerodynamic design is to adjust the seal geometry to flow conditions so that the gas kinetic energy dissipation as even as possible in the seal chambers is obtained.

The novel design method is discussed based on the geometry of a staggered labyrinth seal (Figure 2) of the outer diameter $D$, segment height $H$, radial clearance $R C$, segment length $L S$, pitch $L P$, and tooth thickness $B$.

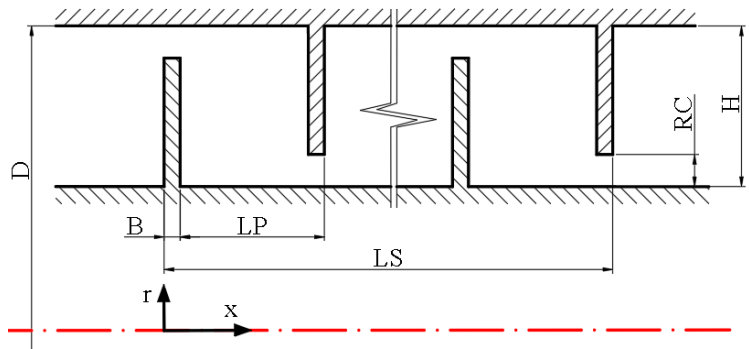

Figure 2. Illustrative geometry of a staggered labyrinth seal.

The design method presented in this paper is based on CFD calculations pertaining to gas flow in the labyrinth seal.

Labyrinth seals have axisymmetric geometries, therefore the flow can be described along the axis $X$. In the method presented herein, calculations were based on the local non-dimensional coordinate $x$ of the seal length being parallel to the seal axis. The origin of the coordinate system is determined at the place being the beginning of the first seal tooth on the gas inflow side. The end of the non-dimensional coordinate system is located at the end of the segment (Figure 2). Hence,

$$
x=\frac{X}{L S} .
$$


The method consists in the analysis of the kinetic energy $E(x)$ distribution in the axial direction (the main flow) within the seal area. The gas kinetic energy in the axial direction was described by the dependency

$$
E(x)=\frac{u^{2}}{2}
$$

where $u$ denotes the gas velocity in the axial direction. Non-dimensional kinetic energy was defined as follows:

$$
e=\frac{E(x)-E_{\min }}{E_{\max }-E_{\min }},
$$

where $E_{\text {min }}$ and $E_{\text {max }}$ denote the minimal and maximal gas kinetic energy, respectively, in the axial direction in the seal. For calculations it was assumed that $E_{\min }=0$.

Illustrative fields of non-dimensional gas kinetic energy $e$ are shown in Figure 3. To improve the readability of the Figure 3, the scale was set within the range from 0 to 0.6 .

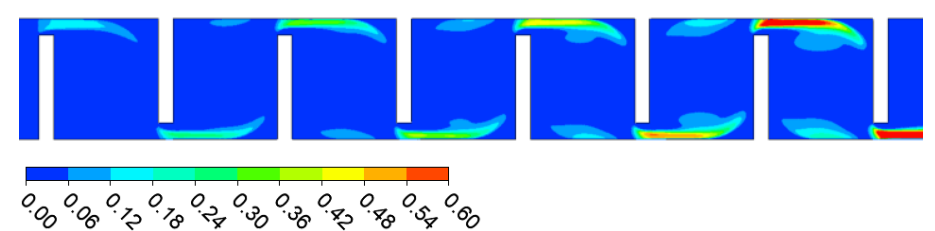

Figure 3. Example distribution of non-dimensional kinetic energy e in the axial direction in the staggered seal for $p_{\text {in }} / p_{\text {out }}=2, T_{\text {in }}=300 \mathrm{~K}, p_{\text {out }}=10^{5} \mathrm{~Pa}$.

The initial stage of the method of adjusting the seal geometry to flow conditions is searching for local maximal non-dimensional values of the gas kinetic energy in the axial direction. In staggered labyrinth seals local maxima of the kinetic energy occur in the area of clearances and in seal chambers just behind clearances (Figure 3).

Illustrative distribution of local maxima of non-dimensional kinetic energy $e_{\max }(i)$ occurring in the staggered seal with the approximation function $e(x)$ is shown in Figure 4 .

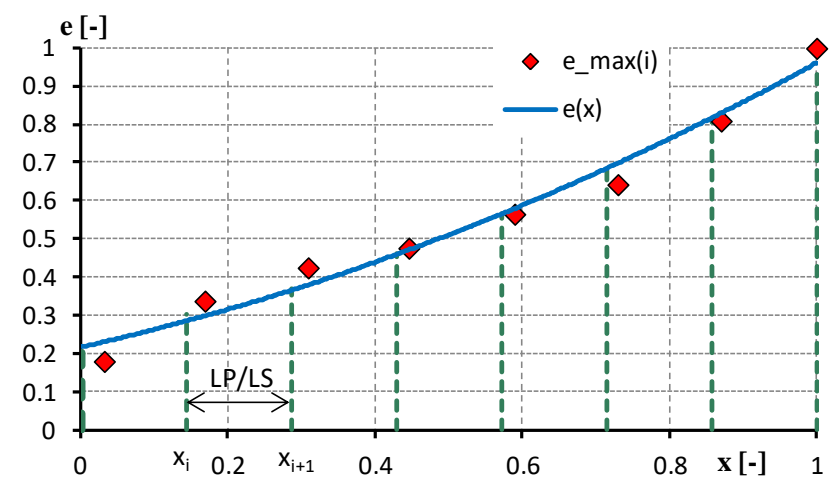

Figure 4. Local maxima of non-dimensional gas kinetic energy $e_{\max }(i)$ in the staggered seal with the approximating line $e(x)$; discontinuous green line shows the location of tooth sidewalls on the inflow side (the distance between them is $L P$ ).

In non-dimensional coordinates, the field below the approximating line, hereinafter designated as $e(x)$, (Figure 4$)$, is divided into $n$ areas with beginnings and ends included between points $\left(x_{i}, x_{i+1}\right)$ for $i=1,2, \ldots, n+1$. The number $n$ of areas is equal to the number of chambers in the seal segment, and their length corresponds with the length of pitch $x_{i+1}-x_{i}=L P$ of the initial geometry.

The area below the approximating curve can be described as follows:

$$
A_{e}=\int_{0}^{1} e(x) d x=\sum_{i=1}^{n} A_{e}(i)
$$


where fields of respective areas are as follows:

$$
A_{e}(i)=\int_{x_{i}}^{x_{i+1}} e(x) d x, \text { where } i=1,2, \ldots, n .
$$

Fields below the curve $e(x)$ of respective areas are proportional by weight to the length of respective pitches of the new geometry.

The length of respective pitches of the improved geometry results from the following equation:

$$
L P(i)=L S \frac{A_{e}(i)}{A_{e}} .
$$

As a result of the applied method, a variable pitch length of the seal adapted to the flow conditions was obtained. Depending on the possibility of changing the inner diameter and the external geometry of the seal, two variants of the method were specified.

\subsection{Variant $A$ of the Design Method}

Variant A of the design method consists in relevant arrangement of the seal teeth. Pitch lengths are determined according to the Equation (6) without changing the length LS and height $\mathrm{H}$ of the seal (Figure 2). External dimensions of the seal do not change in this variant. It can be applied for cases when there is no place for increasing the height of the seal in the geometry of the flow machine.

\subsection{Variant $B$ of the Design Method}

Variant $B$ of the design method can be applied when the change of the height of the seal chambers in the flow machine design is possible. This variant consists in changing the pitch lengths according to the Equation (6) without changing the length $L S$ and with adapting the height of respective seal chambers to the flow conditions. The application of variant $B$ results in obtaining variable chamber volumes in such a way that chambers are increasing in the direction of the gas flow (Figure 5). Illustrative diagram of the staggered seal geometry after the variant B of the design method was applied, is presented in Figure 5.

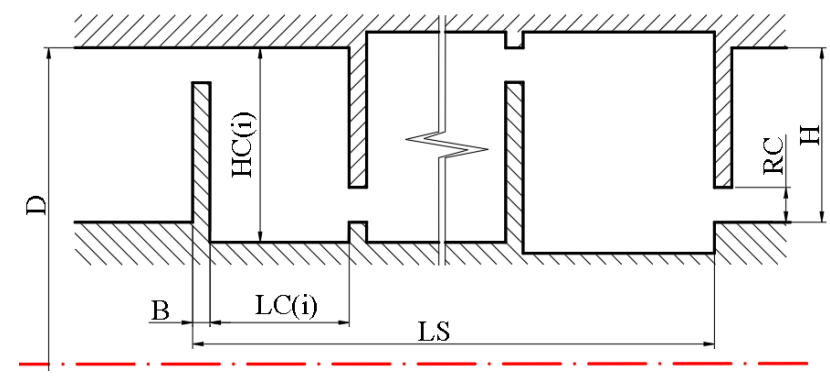

Figure 5. Diagram of geometry as per the comprehensive design method.

Variable chambers' height is selected so that the height of the last chamber is equal to its length $H C(n)=L C(n)$. It was assumed that the variability of chambers' height $H C(i)$ is linear, which can be described by the dependence:

$$
H C(i)=H+(L C(n)-H) \frac{i}{n},
$$

where $n$ is the number of the seal chambers, $i=1,2, \ldots, n$.

Furthermore, it was assumed that the new geometry has clearances of the same flow field as the initial geometry. Height $H$ and diameter $D$ of the inlet and of the outlet channels are also the same as in the initial geometry. 


\subsection{Assumptions for CFD Calculations}

CFD calculations were performed using Ansys Fluent 19. The investigated geometry has inflow section of the length of $6 \mathrm{H}$ (Figure 6), where $H$ denotes the height of the inflow channel (Figure 2). The length of the outflow section was assumed as $11 \mathrm{H}$. At the inlet to the seal, the total pressure $p_{\text {in }}$ and temperature $T_{\text {in }}$ are known, while downstream the segment the static pressure $p_{\text {out }}$ is known. Based on the above boundary conditions (Table 1.) CFD calculations are performed.

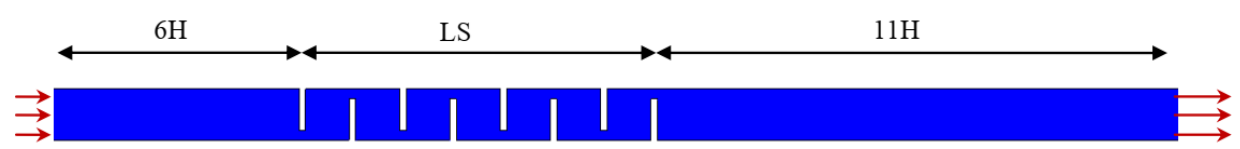

Figure 6. Computation domain.

Table 1. Boundary conditions.

\begin{tabular}{ccc}
\hline Surface & Parameter & Value \\
\hline inlet & total pressure & $2 \cdot 10^{5}-2.8 \cdot 10^{5} \mathrm{~Pa}$ \\
outlet & total temperature & $300 \mathrm{~K}$ \\
walls & static pressure & $10^{5} \mathrm{~Pa}$ \\
\hline
\end{tabular}

In these calculations air was treated as the compressible ideal gas. RANS type calculations were performed for 2D axisymmetric geometry. Equations (8)-(10) were taken into account in the CFD calculations. The continuity equation

$$
\nabla(\rho \vec{v})=0
$$

and the momentum conservation equation

$$
\nabla(\rho \vec{v} \vec{v})=-\nabla p+\nabla \cdot \vec{\tau}
$$

where $\vec{\tau}$ is the stress tensor, was analyzed. The energy conservation equation [39] was considered

$$
\nabla\left(\vec{v}\left(\rho E_{t}+p\right)\right)=\nabla\left(k_{e f f} \nabla T+\left(\vec{\tau}_{e f f} \cdot \vec{v}\right)\right),
$$

where $E_{t}$ is the total energy, $\mathrm{k}_{\text {eff }}$ is the effective thermal conductivity, $\vec{\tau}_{\text {eff }}$ is the deviatoric stress tensor.

The next part of the paper deals with the method of selection of the grid for CFD calculations according to [40]. The grid convergence method was used, which is based on the Richardson extrapolation method. In order to select the mesh, a representative mesh size $h$ was used

$$
h=\left[\frac{1}{N} \sum_{i=1}^{N}\left(\Delta A_{i}\right)\right]^{1 / 2} .
$$

where $\Delta A_{i}$ is area of the $i$-th cell, and $N$ is total number of cells. Three significantly different mesh sets were selected for the analysis. In order to determine the mass flux change calculations were performed for the boundary conditions given in the Table 1 $\left(p_{\text {in }}=2 \cdot 10^{5} \mathrm{~Pa}\right)$. Let $h_{1}<h_{2}<h_{3}$ and $r_{21}=h_{2} / h_{1}, r_{32}=h_{3} / h_{2}$ then calculate the apparent order $p$ of the method using the expression

$$
p=\frac{1}{\ln \left(r_{21}\right)}|\ln | \varepsilon_{32} / \varepsilon_{21}|+q(p)|
$$




$$
\begin{gathered}
q(p)=\ln \left(\frac{r_{21}^{p}-s}{r_{32}^{p}-s}\right) \\
s=1 \cdot \operatorname{sgn}\left(\varepsilon_{32} / \varepsilon_{21}\right)
\end{gathered}
$$

where $\varepsilon_{21}=\dot{m}_{2}-\dot{m}_{1}$ and $\varepsilon_{32}=\dot{m}_{3}-\dot{m}_{2}$.

Extrapolated mass flow was calculated from expression

$$
\dot{m}_{\text {ext }}^{21}=\left(r_{21}^{p} \dot{m}_{1}-\dot{m}_{2}\right) /\left(r_{21}^{p}-1\right) .
$$

Then the following parameters were calculated and reported, along with the apparent order $p$ :

- Approximate relative error,

$$
e_{a}^{21}=\left(\dot{m}_{1}-\dot{m}_{2}\right) / \dot{m}_{1}
$$

- Extrapolated relative error,

$$
e_{e x t}^{21}=\left(\dot{m}_{e x t}^{21}-\dot{m}_{1}\right) / \dot{m}_{e x t}^{21}
$$

- The fine-grid convergence index,

$$
\mathrm{GCI}_{\text {fine }}^{21}=\frac{1.25 e_{a}^{21}}{\left(r_{21}^{p}-1\right)} .
$$

The analysis was performed for the initial geometry with dimensions given in point 3 and exact geometry presented in Figure 10a $(t=8, L P=4 \mathrm{~mm}, R C=0.315 \mathrm{~mm})$. The results are summarized in Table 2.

Table 2. Parameters used in the grid convergence method [40].

\begin{tabular}{ccc}
\hline Parameter & Mark & Value \\
\hline \multirow{3}{*}{ Total number of cells } & $N_{1}$ & 350,000 \\
& $N_{2}$ & 290,378 \\
& $N_{3}$ & 120,812 \\
\hline \multirow{2}{*}{ Mass flux difference } & $r_{21}$ & $1.104[-]$ \\
& $r_{32}$ & $1.55[-]$ \\
\hline Mass flow & $\dot{m}_{1}$ & $0.01981[\mathrm{~kg} / \mathrm{s}]$ \\
& $\dot{m}_{2}$ & $0.01986[\mathrm{~kg} / \mathrm{s}]$ \\
Apparent order & $\dot{m}_{3}$ & $0.0201[\mathrm{~kg} / \mathrm{s}]$ \\
\hline \multirow{2}{*}{ Extrapolated mass flow } & $p$ & $0.598[-]$ \\
\hline Approximate relative error & $\dot{m}_{\text {ext }}^{21}$ & $0.01967[\mathrm{~kg} / \mathrm{s}]$ \\
\hline Extrapolated relative error & $\dot{m}_{\text {ext }}^{32}$ & $0.01968[\mathrm{~kg} / \mathrm{s}]$ \\
\hline Fine-grid convergence index & $e_{a}^{21}$ & $0.042[\%]$ \\
\hline
\end{tabular}

According to Table 2, the obtained numerical uncertainty for the fine grid solution $\mathrm{N}_{1}$ is $0.86 \%$. This is a satisfactory value. The grid with the number of approximately $\mathrm{N}_{1}=354,000$ elements was used for further analysis. In boundary layers, approx. 20 grid cells were assumed. Illustrative grid taken for calculations is shown in Figure 7. The $k-\omega$ SST turbulence model [41] was included in calculations. To obtain the grid of appropriate quality for the $k-\omega$ SST model, the condition that $\mathrm{y}^{+}<2$ in the boundary layer was assumed. 


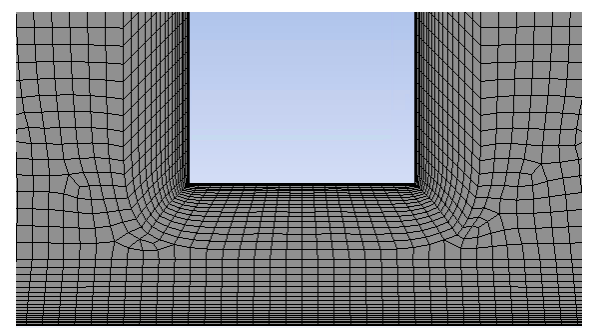

Figure 7. Illustrative grid used for calculations.

Stationary calculations were performed using the pressure-based coupled solver. Convergence tolerance of $4 \times 10^{-6}$ was assumed for calculations. To obtain the required convergence criterion, for each case approx. 150 iterations of calculations were made.

For the model research presented in this paper, CFD simulations were performed for similar grid parameters and the same solver settings as those described in papers $[15,24]$. The same working medium and similar boundary conditions as in $[15,24]$ were applied. Relative mass-flux error between the values obtained experimentally and from CFD calculations for the segment of the straight-through seal [15] was within the range from 0.3 to $0.7 \%$.

This paper presents initial analysis of the new design method. It was decided to perform two-dimensional calculations due to reduced calculation time for many geometries and various boundary conditions. Data shown in the paper [42] indicate that the rotational speed has a little impact on the gas leakage value. Therefore, the impact of the rotational speed was not included in the general CFD analysis.

\section{Application of the Method of Aerodynamic Design for the Staggered Seal of the Geometry Similar to the Element of the Front Sealing in Turbine 13CK60}

The staggered seal consisting of eight teeth located alternately on the shaft and on the body of the sealing (Figure 2) was analyzed. The initial geometry is the staggered seal segment of the external diameter $D=139.9 \mathrm{~mm}$, length $L S=28.5 \mathrm{~mm}$, height $H=4 \mathrm{~mm}$, equal pitch $L P=4 \mathrm{~mm}$, the tooth thickness $B=0.5 \mathrm{~mm}$, and the clearance height $R C=0.315 \mathrm{~mm}$ (Figure 2). The paper presents preliminary research. CFD calculations were performed for perfect air. Distribution of local maxima of non-dimensional kinetic energy dependent on the non-dimensional segment length, obtained from the CFD simulation, is shown in Figure 8.

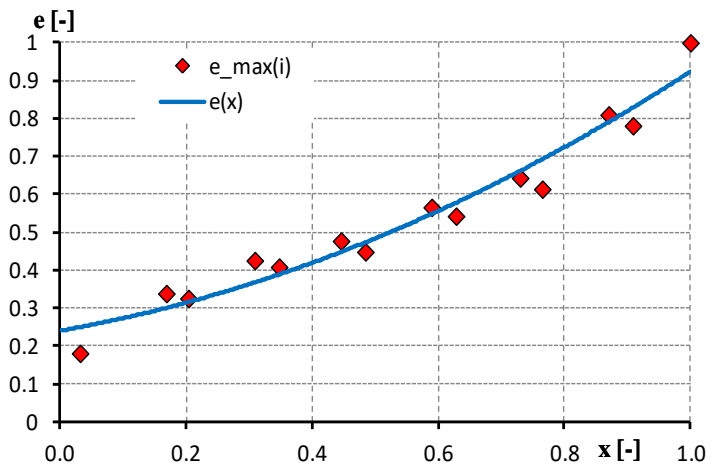

Figure 8. Local maxima of the non-dimensional gas kinetic energy $\mathrm{e}_{\max }(\mathrm{i})$ in the staggered seal with the approximating line $e(x)$ for boundary conditions $p_{\text {in }} / p_{\text {out }}=2, T_{\text {in }}=300 \mathrm{~K}, p_{\text {out }}=10^{5} \mathrm{~Pa}$.

Within the area of the first and last clearances, one local maximum of the kinetic energy was obtained (Figure 8). In other clearances two local maxima of the kinetic energy $e_{\max }(i)$ were obtained. As a result of the design method, variable lengths of the seal pitches $L P(i)$ were obtained. The first seal pitch is $2.04-\mathrm{mm}$ long and the last one is $6.58-\mathrm{mm}$ long (Figure 9). 


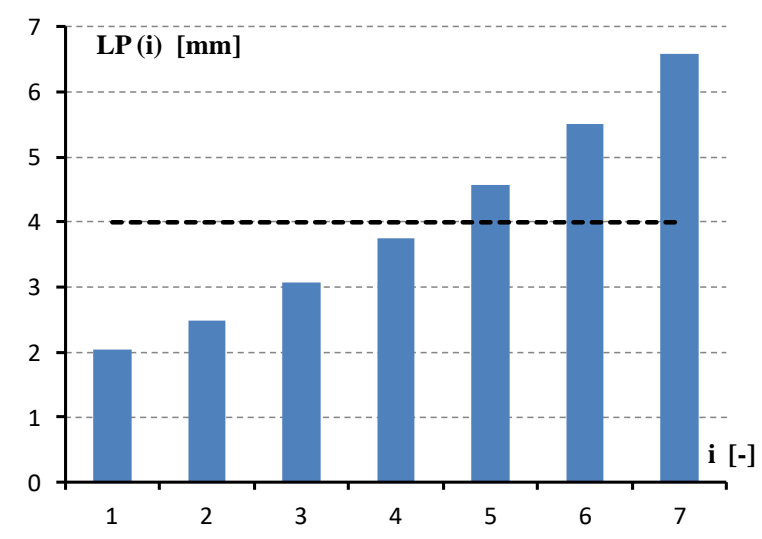

Figure 9. Resultant distribution of the staggered seal pitch lengths; discontinuous line marks the constant length of the pitch of the initial geometry.

The application of the design method results in the reduction of the leakage rate. To present results, a relative leakage change for the new geometry had been defined, which was in turn compared with the initial geometry comprising eight teeth, which was described by the following formula

$$
\delta \dot{m}(t, 8)=\frac{\dot{m}_{\text {LPconst }}(8)-\dot{m}_{L P d m}(t)}{\dot{m}_{\text {LPconst }}(8)} \times 100 \%
$$

The relative leakage change between the geometry of the seal with equal pitch and the improved one with the same number of teeth $t$ was described by the relation

$$
\delta \dot{m}(t)=\frac{\dot{m}_{L P c o n s t}(t)-\dot{m}_{L P d m}(t)}{\dot{m}_{L P c o n s t}(t)} \times 100 \%
$$

Further part of the paper presents results obtained with the use of the design method without changing external dimensions according to the variant $A$ and results of the variant $B$ with a slight change of the seal height.

\subsection{Application of the Variant A of the Design Method}

In this chapter, the impact of the variant A application on the leakage rate for various number of the seal teeth is analyzed. Figure 10 presents the gas velocity contours for the initial geometry and the improved one.

For the geometries under consideration (Figure 10) of uniformly spaced teeth, the change of gas velocity along the seal length is great. The gas velocity in the first clearance is approx. $70 \mathrm{~m} / \mathrm{s}$, and in the last one it exceeds $180 \mathrm{~m} / \mathrm{s}$. The effect of gas expansion in clearances impacts the intensity of gas vortices in subsequent chambers. The vortex in the last chambers is significantly greater than in the first few chambers. In the designed geometry, it was observed that chamber lengths were adapting to the increasing gas velocity in clearances. In result, the gas velocity close to the last tooth (upstream the clearance) is significantly smaller for the designed geometry, when compared with the initial geometry for cases $8 t, 9 t$, and $10 t$, being considered. When the distribution of the gas velocity in the optimized geometries of 9 and 10 teeth is analyzed, it can be observed that gas vortices occur within the whole chambers' volume. Table 3 summarizes obtained values of mass flow for geometries shown in Figure 10. 


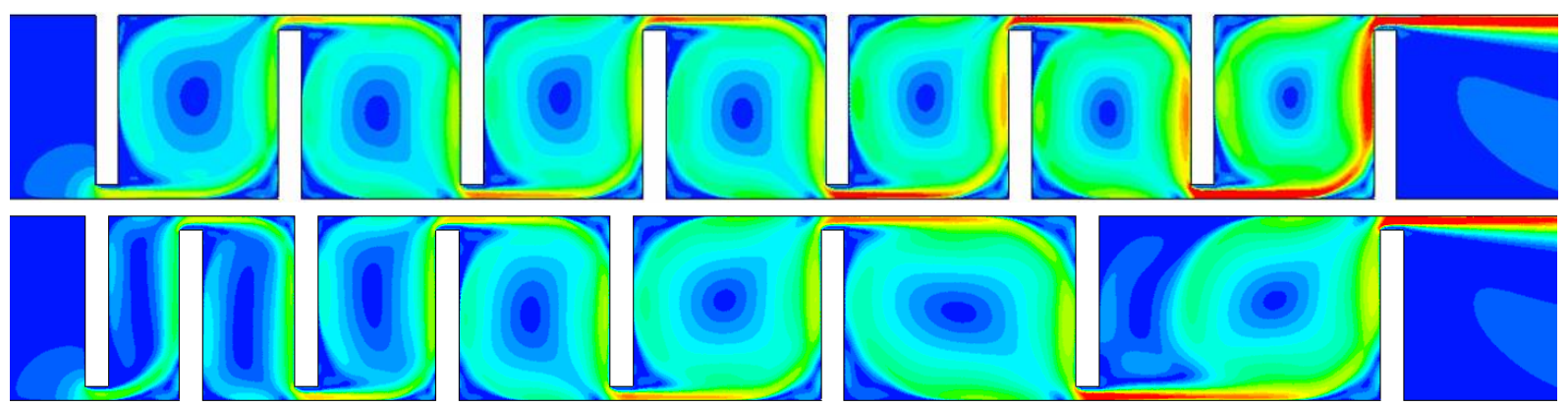

(a)

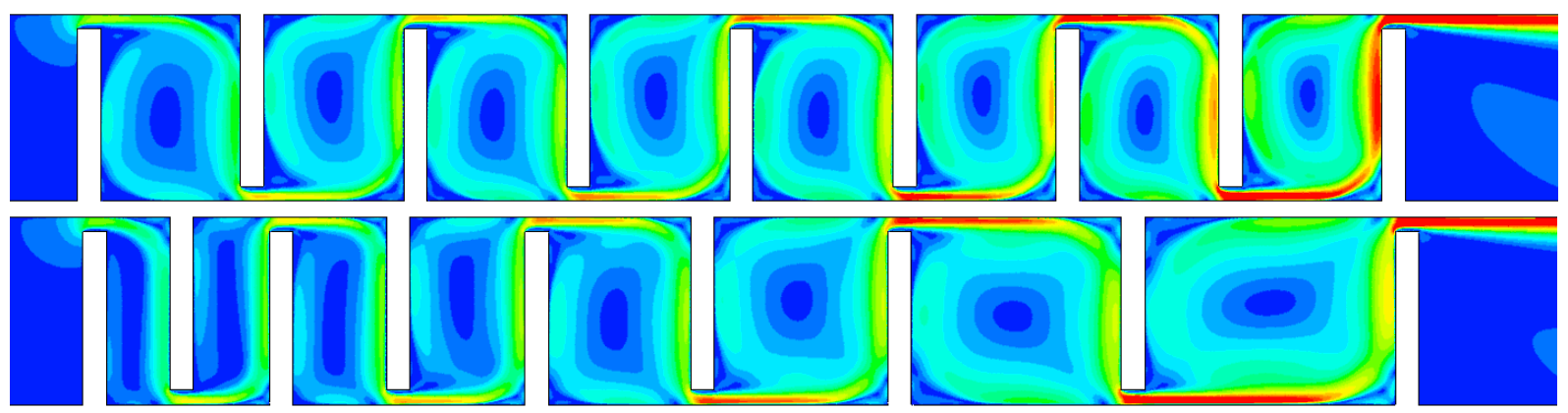

(b)

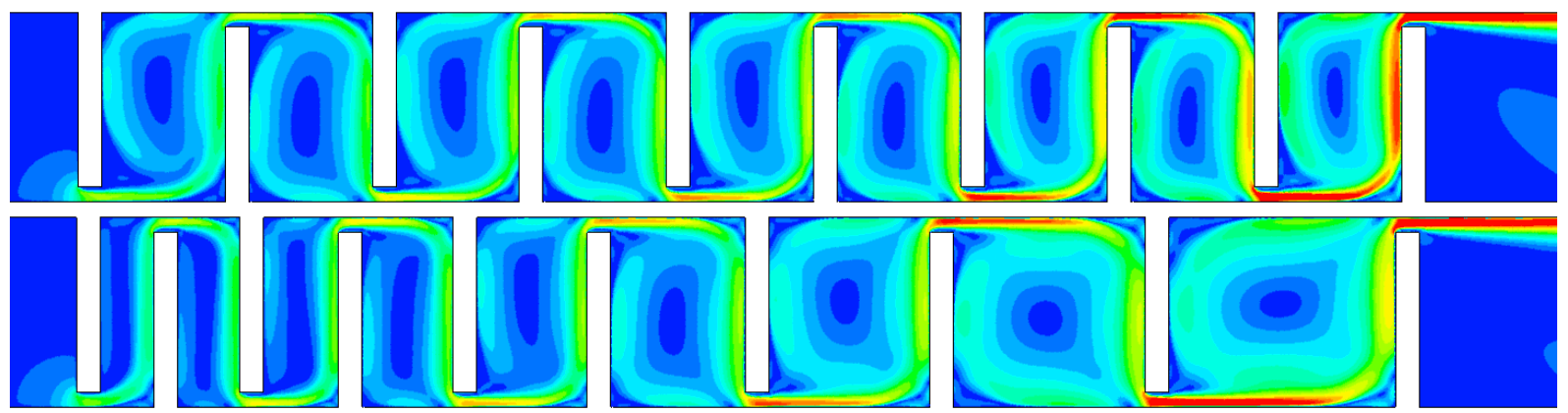

(c)

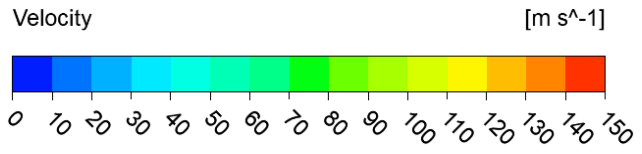

Figure 10. Distribution of air velocity in the seal of the initial geometry and of the designed one for the radial height $\mathrm{RC}=0.315 \mathrm{~mm}$ comprising of (a) eight, (b) nine, and (c) ten teeth for boundary conditions $p_{\text {in }} / p_{\text {out }}=2.4, T_{\text {in }}=300 \mathrm{~K}$, $p_{\text {out }}=10^{5} \mathrm{~Pa}$.

Table 3. Leakage rate for the seal of the initial geometry and of the designed one and their relative changes according to Equations (17) and (18), $\mathrm{RC}=0.315 \mathrm{~mm}$ and of different number of teeth for $p_{\text {in }} / p_{\text {out }}=2, T_{\text {in }}=300 \mathrm{~K}, p_{\text {out }}=10^{5} \mathrm{~Pa}$.

\begin{tabular}{ccccc}
\hline$t$ & $\dot{m}_{\text {LPconst }}(t)[\mathrm{kg} / \mathrm{s}]$ & $\dot{m}_{L P d m}(t)[\mathrm{kg} / \mathrm{s}]$ & $\delta \dot{m}(t, 8)[\%]$ & $\delta \dot{m}(t)[\%]$ \\
\hline 8 & 0.0198 & 0.0191 & 3.4 & 3.4 \\
9 & 0.0184 & 0.0179 & 9.7 & 2.8 \\
10 & 0.0171 & 0.0167 & 15.5 & 2.2 \\
\hline
\end{tabular}

The design method for geometries $8 t, 9 t$, and 10t, when compared to the geometry $8 t$ with evenly spaced teeth (constant pitch length) LPconst (Figure 10a), improves the leaktightness of the relative value $\delta \dot{m}(t, 8)$ by $3.4 \%, 9.7 \%$, and $15.5 \%$, respectively. Comparing the relative difference of the mass flow (Table 3, Figure 11) obtained for the designed geometry $\dot{m}_{L P d m}(t)$ and the geometry with evenly spaced teeth $\dot{m}_{L P c o n s t}(t)$ according to 
the Equation (12), the leak-tightness was improved by $3.4 \%, 2.8 \%$, and $2.2 \%$, respectively, for the geometry $8 \mathrm{t}, 9 \mathrm{t}$, and $10 \mathrm{t}$.

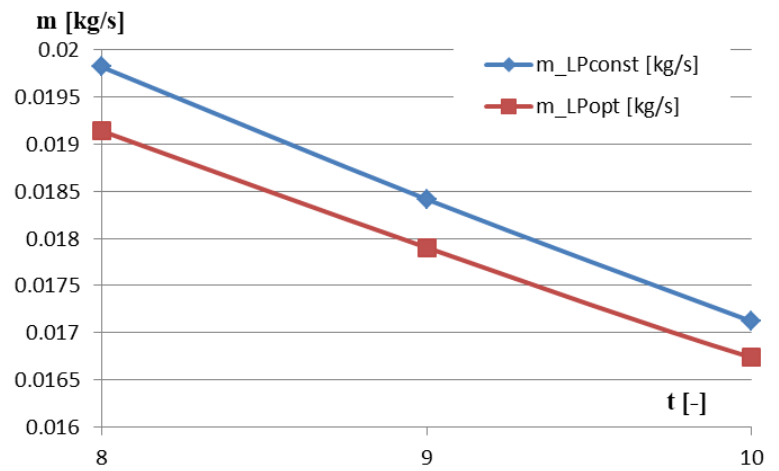

Figure 11. Mass flow obtained for the seal of equal pitch and for the designed one depending on the number of teeth $\mathrm{t}$, for the clearance $\mathrm{RC}=3.15 \mathrm{~mm}$ and boundary conditions $p_{\text {in }} / p_{\text {out }}=2, T_{\text {in }}=300 \mathrm{~K}$, $p_{\text {out }}=10^{5} \mathrm{~Pa}$.

Application of the design method and changing the number of teeth from eight to ten enable significant reduction of the leakage. There is a linear relationship between the number of teeth in the range from 8 and 10 and the relative reduction of the leakage rate for $p_{\text {in }} / p_{\text {out }}=2$ (Figure 12). The limitation of the applied design method for the given seal length LS and many teeth is obtaining too small spaces between them. Therefore, the analysis has not been continued for a greater number of teeth.

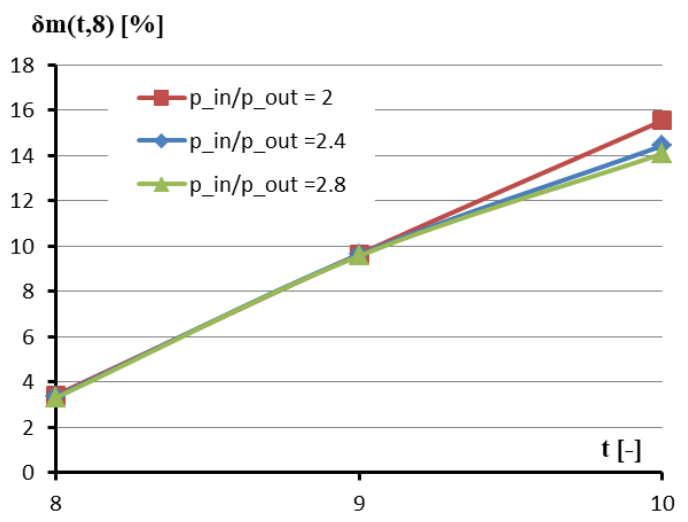

Figure 12. Relative reduction of the integrity of the designed geometry $\delta \dot{m}(t, 8)[\%]$ depending on the number of teeth $\mathrm{t}$, for the clearance $\mathrm{RC}=0.315 \mathrm{~mm}$ and the pressure ratio $p_{\text {in }} / p_{\text {out }}, T_{\text {in }}=300 \mathrm{~K}$, $p_{\text {out }}=10^{5} \mathrm{~Pa}$.

Distribution of flow and thermodynamic parameters of the seal is affected by the ratio of pressure upstream and downstream the sealing. For the ratio $p_{i n} / p_{\text {out }}$ equal to 2.4 and 2.8 , the increase of leakage rate for the designed geometry with 10 teeth was observed (Figure 12). Within the frames of research work a series of numerical calculations was performed for the geometry of the clearance height $\mathrm{RC}=0.315 ; 0.542$ and $0.77 \mathrm{~mm}$ for the pressure ratio $p_{\text {in }} / p_{\text {out }}$ ranging from 2 to 2.8 . Tables $4-6$ summarize the obtained values of air mass flow for the initial geometry and the designed one for various heights of the radial clearance RC. 
Table 4. Change of the leakage rate by Equation (17) depending on the pressure ratio $\mathrm{p}_{\text {in }} / \mathrm{p}_{\text {out }}$ for the initial $8 \mathrm{t}$ and the designed geometry $9 \mathrm{t}$ of the staggered seal, $\mathrm{RC}=0.315 \mathrm{~mm}, T_{\text {in }}=300 \mathrm{~K}$, $p_{\text {out }}=10^{5} \mathrm{~Pa}$.

\begin{tabular}{ccccc}
\hline$p_{\text {in }} / p_{\text {out }}[-]$ & $\dot{m}_{\text {LPconst }}(t=8)[\mathrm{kg} / \mathrm{s}]$ & $\dot{m}_{L P d m}(t=9)[\mathrm{kg} / \mathrm{s}]$ & $\delta \dot{m}(t, 8)[\%]$ & $\Delta \dot{m}[\mathrm{~kg} / \mathrm{s}]$ \\
\hline 2 & 0.0198 & 0.0179 & 9.65 & 0.0019 \\
2.2 & 0.0224 & 0.0202 & 9.62 & 0.0022 \\
2.4 & 0.0249 & 0.0225 & 9.62 & 0.0024 \\
2.6 & 0.0273 & 0.0247 & 9.62 & 0.0026 \\
2.8 & 0.0297 & 0.0269 & 9.57 & 0.0028 \\
\hline
\end{tabular}

Table 5. Change of the leakage rate by Equation (17) depending on the pressure ratio $p_{\text {in }} / p_{\text {out }}$ for the initial $8 \mathrm{t}$ and the designed geometry $9 \mathrm{t}$ of the staggered seal, $\mathrm{RC}=0.542 \mathrm{~mm}, T_{\text {in }}=300 \mathrm{~K}$, $p_{\text {out }}=10^{5} \mathrm{~Pa}$.

\begin{tabular}{ccccc}
\hline$p_{\text {in }} / p_{\text {out }}[-]$ & $\dot{m}_{\text {LPconst }}(t=8)[\mathrm{kg} / \mathrm{s}]$ & $\dot{m}_{\text {LPdm }}(t=9)[\mathrm{kg} / \mathrm{s}]$ & $\delta \dot{m}(t, 8)[\%]$ & $\Delta \dot{m}[\mathrm{~kg} / \mathrm{s}]$ \\
\hline 2 & 0.0302 & 0.0269 & 10.78 & 0.0033 \\
2.2 & 0.0341 & 0.0304 & 10.87 & 0.0037 \\
2.4 & 0.0379 & 0.0338 & 10.89 & 0.0041 \\
2.6 & 0.0416 & 0.0371 & 10.90 & 0.0045 \\
2.8 & 0.0453 & 0.0404 & 10.90 & 0.0049 \\
\hline
\end{tabular}

Table 6. Change of the leakage rate by Equations (17) and (18) depending on the pressure ratio $p_{\text {in }} / p_{\text {out }}$ for the initial $8 \mathrm{t}$ and the designed geometry $9 \mathrm{t}$ of the staggered seal, $\mathrm{RC}=0.77 \mathrm{~mm}, T_{i n}=300 \mathrm{~K}$, $p_{\text {out }}=10^{5} \mathrm{~Pa}$.

\begin{tabular}{ccccc}
\hline$p_{\text {in }} / p_{\text {out }}[-]$ & $\dot{m}_{\text {LPconst }}(t=8)[\mathrm{kg} / \mathrm{s}]$ & $\dot{m}_{\text {LPdm }}(t=9)[\mathrm{kg} / \mathrm{s}]$ & $\delta \dot{m}(t, 8)[\%]$ & $\Delta \dot{m}[\mathrm{~kg} / \mathrm{s}]$ \\
\hline 2 & 0.0385 & 0.0343 & 10.95 & 0.0042 \\
2.2 & 0.0435 & 0.0388 & 10.95 & 0.0048 \\
2.4 & 0.0484 & 0.0431 & 10.80 & 0.0052 \\
2.6 & 0.0532 & 0.0474 & 10.76 & 0.0057 \\
2.8 & 0.0580 & 0.0517 & 10.97 & 0.0064 \\
\hline
\end{tabular}

The relative reduction of the leakage $\delta \dot{m}(t)$ for geometries of the staggered seal under consideration is slightly affected by the pressure ratio $p_{\text {in }} / p_{\text {out }}$. For geometries $\mathrm{RC}=0.315$, $0.542,0.77 \mathrm{~mm}$, it is included in the range $9.57-9.65 \%, 10.78-10.90 \%$, and $10.76-10.97 \%$, respectively. The leakage rate reduction depends on the clearance height. The greatest relative reduction of the leakage was obtained for the geometry $\mathrm{RC}=0.542$ and $0.77 \mathrm{~mm}$, $t=8$ (Tables 5 and 6).

For the increasing pressure ratio, the leakage reduction $\Delta \dot{m}$ is linear for the analyzed RC, (Figure 13).

\subsection{Application of the Variant B of the Design Method}

For the geometry as per the variant B (described in Section 2.2.), numerical simulations of air flow for various air pressure ratios $p_{\text {in }} / p_{\text {out }}$ from the range 2-2.8 were performed.

In the geometry with chambers of variable height the gas velocity field is more complex than in the geometry from the variant A. During the analysis of the distribution of the gas velocity, a better adaptation of chambers' size to the gas vortex can be observed, when compared with the variant $\mathrm{A}$. The higher is the gas velocity in the clearance, the greater are the chambers' volume and vortex.

The gas velocity before clearances is significantly lower than in the variant A (Figure 14). Furthermore, a significantly weaker gas stream of a high velocity is observed in chambers behind clearances. When compared with the initial geometry and data from the variant A, in chambers no. 2, 4, 5, and 6 additional gas vortices were obtained in the area of the outlet from the clearance behind back walls of shorter teeth, which made the gas flow be more dissipative. 


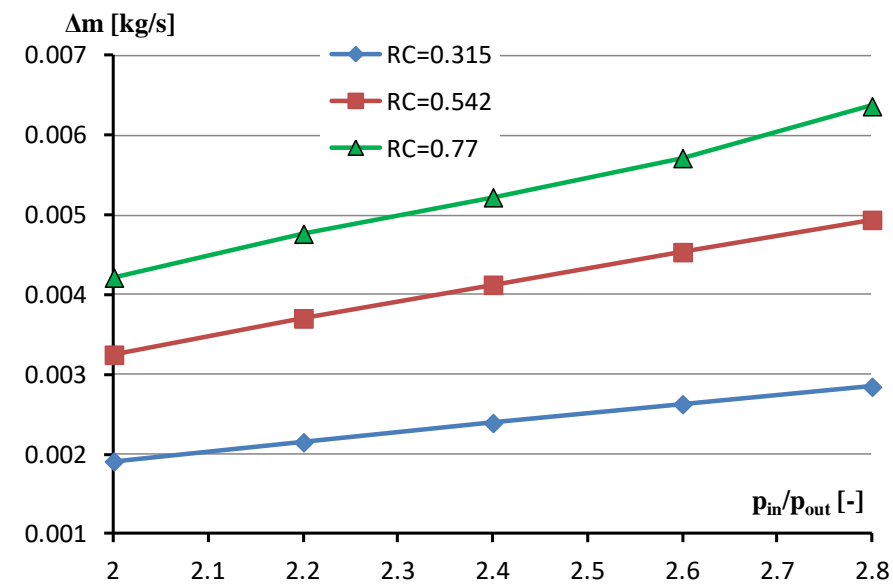

Figure 13. Leakage reduction for geometries $8 \mathrm{t}$ of the clearance height $\mathrm{RC}=0.315,0.542$, and $0.77 \mathrm{~mm}$ depending on the pressure ratio for $T_{\text {in }}=300 \mathrm{~K}, p_{\text {out }}=10^{5} \mathrm{~Pa}$.

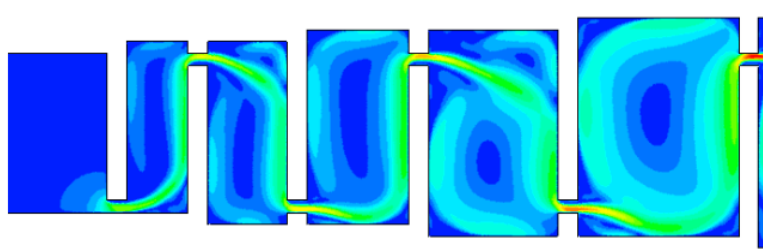

Velocity

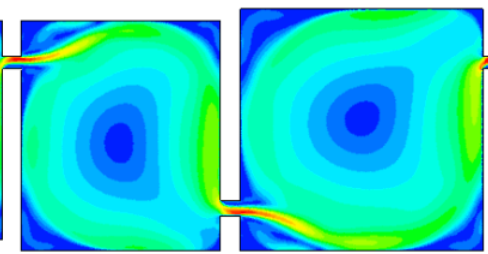

$\left[\mathrm{m} \mathrm{s} \mathrm{s}^{\wedge}-1\right]$

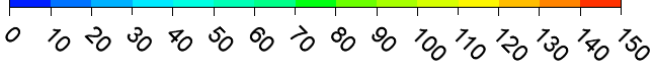

Figure 14. Velocity fields in the designed geometry as per variant $\mathrm{B}$ for $p_{\text {in }} / p_{\text {out }}=2.4, T_{\text {in }}=300 \mathrm{~K}, p_{\text {out }}=10^{5} \mathrm{~Pa}$.

To sum up, more complicated flow results in a significant reduction of the leakage rate. Obtained results concerning the gas mass flow for the geometry in the variant $\mathrm{B}$ are summarized in Table 7.

Table 7. Variant B — change of the leakage rate by Equation (18) depending on the pressure ratio $p_{\text {in }} / p_{\text {out }}$ for the initial geometry $8 \mathrm{t}$ and the improved one of the staggered seal $\mathrm{RC}=0.315 \mathrm{~mm}$, $T_{\text {in }}=300 \mathrm{~K}, p_{\text {out }}=10^{5} \mathrm{~Pa}$.

\begin{tabular}{ccccc}
\hline$p_{\text {in }} / p_{\text {out }}[-]$ & $\dot{m}_{\text {LPconst }}(t=8)[\mathrm{kg} / \mathrm{s}]$ & $\dot{m}_{L P d m}(t=8)[\mathrm{kg} / \mathrm{s}]$ & $\delta \dot{m}(t)[\%]$ & $\Delta \dot{m}[\mathrm{~kg} / \mathrm{s}]$ \\
\hline 2 & 0.0198 & 0.0167 & 15.7 & 0.00311 \\
2.2 & 0.0224 & 0.0189 & 15.5 & 0.00348 \\
2.4 & 0.0249 & 0.0211 & 15.3 & 0.00381 \\
2.6 & 0.0273 & 0.0232 & 15.1 & 0.00413 \\
2.8 & 0.0297 & 0.0252 & 15.2 & 0.00452 \\
\hline
\end{tabular}

Application of the method for the improved spacing of teeth and changing the chambers depth enabled a significant reduction of the leakage rate by approx. $15.4 \%$. The relative reduction of the leakage rate reveals a slightly decreasing trend for growing pressure ratio $p_{\text {in }} / p_{\text {out }}$. It is a good result for the leakage rate reduction when a slight change of the seal height with keeping the length unchanged is taken into consideration. It should be noted that in the designed geometry the gas flow field in clearances has not changed.

Pressure drop has no significant impact on the relative leakage decrease, therefore representative results for Variant A and B are summarized in Table 8. 
Table 8. Summary of change of the leakage rate by Equations (17) and (18) for application of the design method for Variant $\mathrm{A}$ and $\mathrm{B}$, for the initial geometry $(8 \mathrm{t})$ and the improved one $8 \mathrm{t}$ and $9 \mathrm{t}$, $p_{\text {in }} / p_{\text {out }}=2 T_{\text {in }}=300 \mathrm{~K}, p_{\text {out }}=10^{5} \mathrm{~Pa}$.

\begin{tabular}{cccc}
\hline Variant & $\mathrm{RC}[\mathrm{mm}]$ & $\delta \dot{\boldsymbol{m}}(\boldsymbol{t}=8)[\%]$ & $\delta \dot{\boldsymbol{m}}(\boldsymbol{t}=9,8)[\%]$ \\
\hline \multirow{2}{*}{$\mathrm{A}$} & 0.315 & 3.4 & 9.65 \\
& 0.542 & 3.5 & 10.78 \\
$\mathrm{~B}$ & 0.77 & 3.3 & 10.95 \\
\hline
\end{tabular}

Variant A of the method for the geometry without change of teeth number $(t=8)$ brings improvement of leak-tightness $\delta \dot{m}(t)$ in the range from 3.3\% to $3.5 \%$. For geometry with the increased number of teeth (variant $\mathrm{A})$, a significantly reduced leakage $(\delta \dot{m}(t, 8)$ was achieved in the range from $9.65 \%$ to $10.95 \%$. Variant B enables a significant reduction of the leakage (even by $15.7 \%$ ) without the increased number of teeth.

\section{Conclusions}

Minimization of the leakage rate in labyrinth seals is a problem of great importance since it enables improvement of high-power fluid-flow machines efficiency. This paper presented two variants of the method for aerodynamic design of the seal geometry. Variant A can be used when it is impossible to change external dimensions of the seal; it consists in changing the location of the seal teeth. In this variant, the design method anticipates the interference in the geometry of internal elements of the seal. Variant B can be used when there is a possibility to change slightly the height of seal chambers in the fluid-flow machine.

The design method in both variants, A and B, enables improvement of seals in different machines, newly designed as well as already installed but under modernization or repair. This method is based on the observation of thermodynamic and flow phenomena occurring in labyrinth seals, such as the gas flux of a high velocity formation, and the mechanism of kinetic energy dissipation. The above described method allows for determining the resultant geometry unequivocally.

The method in the variant A enables changing the pitch length for the staggered seals to obtain the reduced leakage. For the representative straight through seal geometry the leakage rate reduction ranging from $3.4 \%$ to $15.5 \%$ had been obtained, when compared with the initial geometry of a constant pitch.

The method in the variant $B$ brings significant reduction of the leakage rate by $15.4 \%$ without changing the seal length and with a slight change of the seal height.

Results of calculations presented in this paper confirm the effectiveness of the design method for both variants irrespective of the value of the pressure ratio $p_{\text {in }} / p_{\text {out }}$ in the range from 2 to 2.8. Results presented in the paper show that the use of the improved geometry enables the reduction of leakage of various degrees of wear of the seal, from radial clearance 0.315 to $0.77 \mathrm{~mm}$.

Currently, there is no similar approach to the design of seals in the literature. The method discussed in this article opens up a new perspective on seal design. It is planned to use this design method to other geometries of sealing and to conduct experimental research.

Funding: This research received no external funding.

Institutional Review Board Statement: Not applicable.

Informed Consent Statement: Not applicable.

Data Availability Statement: Not applicable.

Conflicts of Interest: The authors declare no conflict of interest. 


\section{Nomenclature}

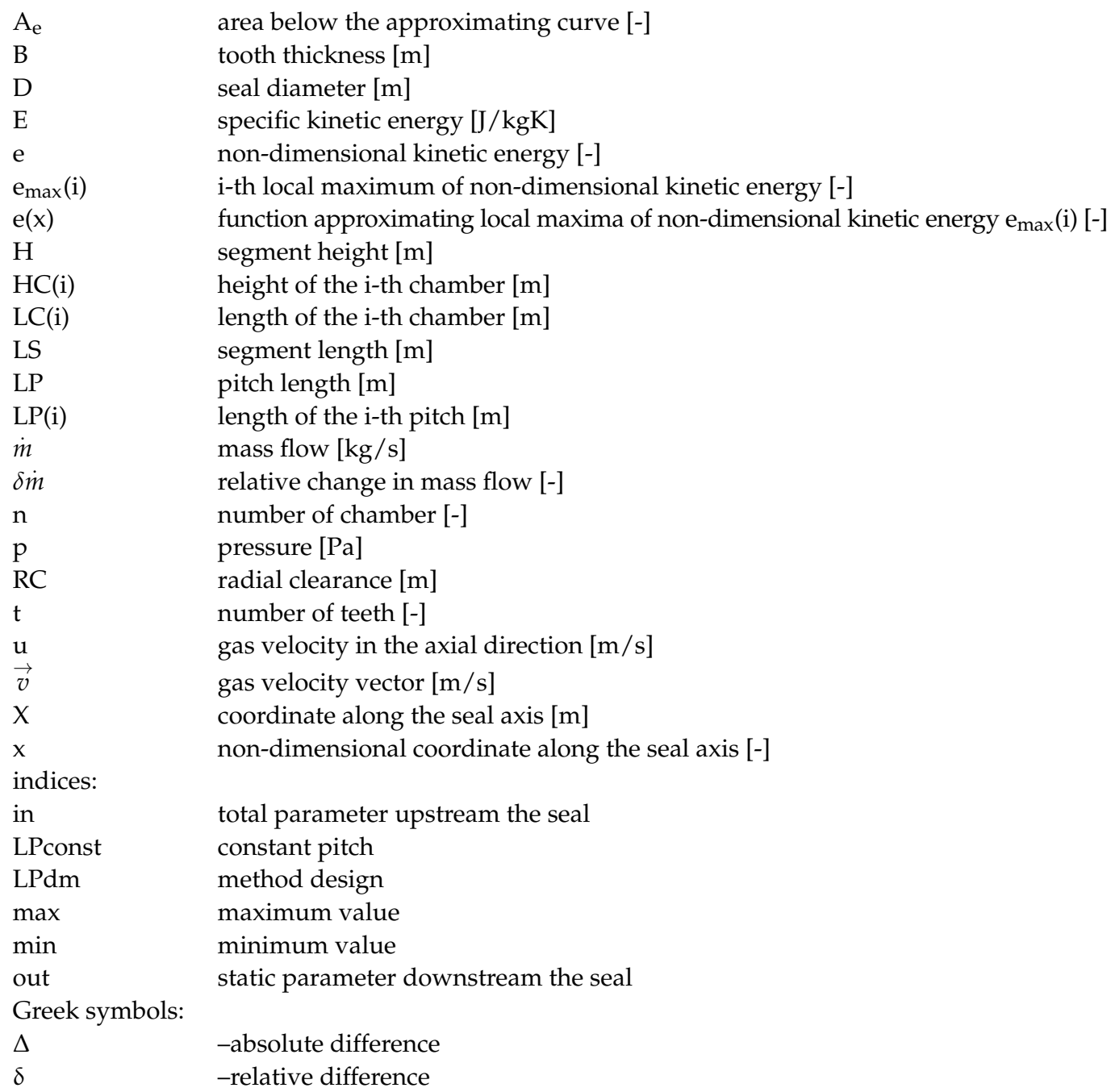

\section{References}

1. Krzyślak, P.; Winowiecki, M. A method of diagnosing labyrinth seals in fluid-flow machines. Pol. Marit. Res. 2008, 15, 38-41. [CrossRef]

2. Anker, J.E.; Mayer, J.F.; Stetter, H. Computational study of the flow in an axial turbine with emphasis on the interaction of labyrinth seal leakage flow and main flow. High Perform. Comput. Sci. Eng. 2002, 1, 363-371.

3. Liang, D.; Jin, D.; Gui, X. Investigation of seal cavity leakage flow effect on multistage axial compressor aerodynamic performance with a circumferentially averaged method. Appl. Sci. 2021, 11, 3937. [CrossRef]

4. Larjola, J.; Honkatukia, J.; Sallinen, P.; Backman, J. Fluid dynamic modeling of a free piston engine with labyrinth seals. J. Therm. Sci. 2010, 19, 141-147. [CrossRef]

5. Feng, J.; Wang, L.; Yang, H.; Peng, X. Numerical Investigation on the Effects of Structural Parameters of Labyrinth Cavity on Sealing Performance. Math. Probl. Eng. 2018, 2018, 5273582. [CrossRef]

6. Graunke, K. Labyrinth leakage flow in a labyrinth-piston compressor. Sulzer Tech. Rev. 1985, 67, 30-33.

7. Martin, H.M. Labyrinth packings. Engineering 1908, 85, 35-38.

8. Egli, A. The leakage of steam through labyrinth seals. Trans. ASME 1935, 57, 115-122.

9. Hodkinson, B. Estimation of the leakage through a labyrinth gland. Proc. Inst. Mech. Eng. 1939, 141, 283-288. [CrossRef]

10. Zimmermann, H.; Wolff, K.H. Comparison Between Empirical and Numerical Labyrinth Flow Correlations. Am. Soc. Mech. Eng. 1987. [CrossRef]

11. Childs, D.W.; Scharrer, J.K. An Iwatsubo-Based Solution for Labyrinth Seals: Comparison to Experimental Results. J. Eng. Gas Turbines Power 1986, 108, 325-331. [CrossRef]

12. Scharrer, J.K. Theory versus Experiment for the Rotordynamic Coefficients of Labyrinth Gas Seals: Part I-A Two Control Volume Model. J. Vib. Acoust. Stress Reliab. 1988, 110, 270-280. [CrossRef]

13. Zhu, G.; Liu, W. Analysis of calculational methods on leakage for labyrinth seals. Lubr. Eng. 2006, 4. 
14. Zhu, Y.; Jiang, Y.; Liang, S.; Guo, C.; Guo, Y.; Cai, H. One-dimensional computation method of supercritical $\mathrm{CO}_{2}$ labyrinth seal. Appl. Sci. 2020, 10, 5771. [CrossRef]

15. Joachimmiak, D.; Krzyslak, P. Analysis of the Gas Flow in a Labyrinth Seal of Variable Pitch. J. Appl. Fluid Mech. 2019, 12, 921-930. [CrossRef]

16. Hur, M.S.; Lee, S.I.; Moon, S.W.; Kim, T.S.; Kwak, J.S.; Kim, D.H.; Jung, I.Y. Effect of clearance and cavity geometries on leakage performance of a stepped labyrinth seal. Processes 2020, 8, 1496. [CrossRef]

17. Baek, S.I.; Ahn, J. Optimizing the Geometric Parameters of a Straight-Through Labyrinth Seal to Minimize the Leakage Flow Rate and the Discharge Coefficient. Energies 2021, 14, 705. [CrossRef]

18. Hur, M.-S.; Moon, S.-W.; Kim, T.-S. A Study on the Leakage Characteristics of a Stepped Labyrinth Seal with a Ribbed Casing. Energies 2021, 14, 3719. [CrossRef]

19. Savvakis, S.; Mertzis, D.; Nassiopoulos, E.; Samaras, Z. A Design of the Compression Chamber and Optimization of the Sealing of a Novel Rotary Internal Combustion Engine Using CFD. Energies 2020, 13, 2362. [CrossRef]

20. Zou, Z.; Shao, F.; Li, Y.; Zhang, W.; Berglund, A. Dominant flow structure in the squealer tip gap and its impact on turbine aerodynamic performance. Energy 2017, 138, 167-184. [CrossRef]

21. Yang, J.; Zhao, F.; Zhang, M.; Liu, Y.; Wang, X. Numerical Analysis of Labyrinth Seal Performance for the Impeller Backface Cavity of a Supercritical $\mathrm{CO}_{2}$ Radial Inflow Turbine. Comput. Model. Eng. Sci. 2021, 126, 935-953. [CrossRef]

22. Č́ižek, M.; Pátek, Z.; Vampola, T. Aircraft turbine engine labyrinth seal CFD sensitivity analysis. Appl. Sci. 2020, 10, 6830. [CrossRef]

23. Joachimiak, D.; Krzyślak, P. Experimental Research and CFD Calculations Based Investigations Into Gas Flow in a Short Segment of a Heavily Worn Straight Through Labyrinth Seal. Pol. Marit. Res. 2017, 24, 83-88. [CrossRef]

24. Joachimiak, D.; Frąckowiak, A. Experimental and Numerical Analysis of the Gas Flow in the Axisymmetric Radial Clearance. Energies 2020, 13, 5794. [CrossRef]

25. Zhou, W.; Zhao, Z.; Wang, Y.; Shi, J.; Gan, B.; Li, B.; Qiu, N. Research on leakage performance and dynamic characteristics of a novel labyrinth seal with staggered helical teeth structure. Alex. Eng. J. 2021, 60, 3177-3187. [CrossRef]

26. Zhirong, L.; Xudong, W.; Xin, Y.; Naoki, S.; Taro, N. Investigation and improvement of the staggered labyrinth seal. Chin. J. Mech. Eng. 2015, 28, 402-408. [CrossRef]

27. Cremanns, K.; Roos, D.; Hecker, S.; Dumstorff, P.; Almstedt, H.; Musch, C. Efficient multi-objective optimization of labyrinth seal leakage in steam turbines based on hybrid surrogate models. In Proceedings of the ASME Turbo Expo 2016: Turbomachinery Technical Conference and Exposition, Seoul, Korea, 13-17 June 2016; Volume 2C-2016, pp. 1-11.

28. Szymanski, A.; Wróblewski, W.; Fraczek, D.; Bochon, K.; Dykas, S.; Marugi, K. Optimization of the Straight-Through Labyrinth Seal With a Smooth Land. J. Eng. Gas Turbines Power 2018, 140, 122503. [CrossRef]

29. Zhao, Y.; Wang, C. Shape Optimization of Labyrinth Seals to Improve Sealing Performance. Aerospace 2021, 8, 92. [CrossRef]

30. Asok, S.P.; Sankaranarayanasamy, K.; Sundararajan, T.; Rajesh, K.; Sankar Ganeshan, G. Neural network and CFD-based optimisation of square cavity and curved cavity static labyrinth seals. Tribol. Int. 2007, 40, 1204-1216. [CrossRef]

31. Joachimiak, D.; Krzyślak, P. A model of gas flow with friction in a slotted seal. Arch. Thermodyn. 2016, 37, 95-108. [CrossRef]

32. Joachimiak, M. Analysis of thermodynamic parameter variability in a chamber of a furnace for thermo-chemical treatment. Energies 2021, 14, 2903. [CrossRef]

33. Frackowiak, A.; Olejnik, A.; Wróblewska, A.; Ciałkowski, M. Application of the protective coating for blade's thermal protection. Energies 2021, 14, 50. [CrossRef]

34. Joachimiak, D.; Krzyślak, P. Comparison of results of experimental research with numerical calculations of a model one-sided seal. Arch. Thermodyn. 2015, 36, 61-74. [CrossRef]

35. Joachimmiak, D. Universal Method for Determination of Leakage in Labyrinth Seal. J. Appl. Fluid Mech. 2020, 13, 935-943. [CrossRef]

36. Eser, D.; Dereli, Y. Comparisons of rotordynamic coefficients in stepped labyrinth seals by using Colebrook-White friction factor model. Meccanica 2007, 42, 177-186. [CrossRef]

37. Wang, W.; Liu, Y.; Jiang, P.; Chen, H. Numerical Analysis of Leakage Flow Through Two Labyrinth Seals. J. Hydrodyn. 2007, 19, 107-112. [CrossRef]

38. Morrison, G.L.; Al-Ghasem, A. Experimental and Computational Analysis of a Gas Compressor Windback Seal. In Proceedings of the ASME Turbo Expo 2007: Power for Land, Sea, and Air, Montreal, ON, Canada, 14-17 May 2007; Volume 4, pp. $1231-1247$.

39. ANSYS, Inc. ANSYS Fluent Theory Guide 15; ANSYS, Inc.: Canonsburg, PA, USA, 2019.

40. Celik, I.B.; Ghia, U.; Roache, P.J.; Freitas, C.J.; Coleman, H.; Raad, P.E. Procedure for estimation and reporting of uncertainty due to discretization in CFD applications. J. Fluids Eng. Trans. ASME 2008, 130, 780011-780014. [CrossRef]

41. Menter, F.R. Two-equation eddy-viscosity turbulence models for engineering applications. AIAA J. 1994, 32, 1598-1605. [CrossRef]

42. Li, J.; Wen, K.; Wang, S.; Jiang, S.; Kong, X. Experimental and numerical investigations on the leakage flow characteristics of labyrinth seals. In Proceedings of the ASME Turbo Expo 2012: Turbine Technical Conference and Exposition, Copenhagen, Denmark, 11-15 June 2012; pp. 164-172. 